\title{
Subgroup analysis of phase 3 studies of dulaglutide in Japanese patients with type 2 diabetes
}

\author{
Yukiko Onishi ${ }^{1)}$, Tomonori Oura ${ }^{2)}$, Hiroshi Nishiyama ${ }^{2)}$, Sumika Ohyama ${ }^{2)}$, Masakazu Takeuchi ${ }^{2)}$ and \\ Noriyuki Iwamoto ${ }^{2)}$ \\ 1) The Institute for Adult Diseases, Asahi Life Foundation, Tokyo, Japan \\ 2) Eli Lilly Japan K.K., Kobe, Japan
}

\begin{abstract}
The efficacy and tolerability of once weekly dulaglutide $0.75 \mathrm{mg}$ in Japanese patients with type 2 diabetes (T2D) were evaluated by subgroups defined by key demographic characteristics. This post hoc analysis included data from patients who received dulaglutide $0.75 \mathrm{mg}$ for up to 26 weeks in three phase 3 trials (one open-label, randomized; one double-blind and open-label, randomized; one open-label, nonrandomized). Patients were classified into subgroups on the basis of sex (male, female), age ( $<65, \geq 65$ years), body weight $\left(<70, \geq 70 \mathrm{~kg}\right.$ ), body mass index (BMI; $\left.<25, \geq 25 \mathrm{~kg} / \mathrm{m}^{2}\right)$, duration of diabetes $(<7, \geq 7$ years), $\mathrm{HbAlc}(\leq 8.5,>8.5 \%)$, use of concomitant sulfonylurea (yes, no), and use of concomitant biguanide (yes, no). Efficacy measures analyzed were changes from baseline in $\mathrm{HbAlc}$ and body weight and percentages of patients achieving HbA1c $<7.0 \%$. Safety measures analyzed were incidence of hypoglycemia and nausea and change from baseline in seated pulse rate. A total of 855 patients were analyzed. Once weekly dulaglutide $0.75 \mathrm{mg}$ improved blood glucose control as measured by HbA1c regardless of patient characteristics; patients with higher baseline HbA1c values had greater improvements compared to patients with lower baseline values. Weight loss was greater in patients with lower baseline $\mathrm{HbAlc}$ and in patients taking concomitant biguanides. Concomitant use of sulfonylureas had the greatest effect on the incidence of hypoglycemia. Treatment of T2D with once weekly dulaglutide $0.75 \mathrm{mg}$ for 26 weeks was associated with significant improvement in glycemic control irrespective of age, sex, duration of diabetes, body weight, BMI, or concomitant medication.
\end{abstract}

Key words: Dulaglutide, GLP-1 receptor agonist, Type 2 diabetes, Subgroup analysis

IT has been approximately 5 years since liraglutide was launched as the first glucagon-like peptide-1 (GLP-1) receptor agonist in Japan. Additional GLP-1 receptor agonists (exenatide twice daily, exenatide once weekly, and lixisenatide) have been launched since then, and these have all become important treatment options for patients with type 2 diabetes (T2D) [1,2].

Dulaglutide is a long-acting GLP-1 receptor agonist that mimics some of the effects of endogenous GLP-1 [3]. It has been approved and launched in the United States and the European Union at once weekly

Submitted Sep. 1, 2015; Accepted Nov. 26, 2015 as EJ15-0518 Released online in J-STAGE as advance publication Dec. 23, 2015

Correspondence to: Masakazu Takeuchi, Ph.D., Eli Lilly Japan K.K., Kobe 651-0086, Japan.

E-mail: takeuchi_masakazu@yahoo.co.jp

Abbreviations: ANCOVA, analysis of covariance; $\mathrm{BG}$, biguanides; BMI, body mass index; CI, confidence interval; GLP-1, glucagonlike peptide-1; LS, least-square; SD, standard deviation; SE, standard error; SU, sulphonylureas; T2D, type 2 diabetes doses of $0.75 \mathrm{mg}$ and $1.5 \mathrm{mg}[4,5]$ and in Japan at a once weekly dose of $0.75 \mathrm{mg}$ [6]. In phase 3 studies in Japanese patients with T2D, once weekly dulaglutide $0.75 \mathrm{mg}$ has shown superiority to insulin glargine (in a randomized, 26-week, open-label study of dulaglutide in combination with sulfonylureas $[\mathrm{SU}]$ and/or biguanides $[\mathrm{BG}]$ ) and non-inferiority to liraglutide 0.9 $\mathrm{mg}$ /day (in a randomized monotherapy study in which dulaglutide was compared to placebo [double-blind] and to liraglutide $0.9 \mathrm{mg} /$ day [open-label]; the study had a 26-week primary endpoint and a 52-week treatment period) in $\mathrm{HbAlc}$ changes [7-9]. Also, in a nonrandomized, open-label, long-term (52-week) phase 3 safety study in Japanese patients with T2D, once weekly dulaglutide $0.75 \mathrm{mg}$ was overall well-tolerated in combination with a single oral hypoglycemic agent (SU, BG, $\alpha$-glucosidase inhibitors, thiazolidinediones, or glinides) [10]. In order to better understand the effects of once weekly dulaglutide in differerent 
patient populations, we pooled the 3 studies described above and evaluated the efficacy and safety of dulaglutide $0.75 \mathrm{mg}$ after 26 weeks of treatment stratified by patient characteristics at baseline.

\section{Materials and Methods}

\section{Patients}

All 3 protocols were approved by each participating center's ethical review board, and the studies were conducted in accordance with the Declaration of Helsinki and Good Clinical Practice guidelines. All patients provided written informed consent before receiving treatment. All 3 studies were registered with ClinicalTrials. gov (NCT01584232, NCT01558271, NCT01468181). Study design and methods for each study have been previously reported [7-10].

\section{Statistical analysis}

The following efficacy parameters were analyzed across the subgroups for dulaglutide-treated patients in the 3 pooled studies after 26 weeks of treatment: changes from baseline in $\mathrm{HbAlc}$ and body weight and proportions of patients achieving $\mathrm{HbA} 1 \mathrm{c}$ target $<7.0 \%$. The following safety parameters were analyzed across the subgroups through 26 weeks of treatment: incidence of hypoglycemia (defined as plasma glucose $\leq 70$ $\mathrm{mg} / \mathrm{dL}$ with or without symptoms), incidence of nausea, and change from baseline in seated pulse rate.

The key patient subgroups analyzed were sex (male, female), age ( $<65, \geq 65$ years), duration of T2D $(<7$, $\geq 7$ years), baseline body weight ( $<70, \geq 70 \mathrm{~kg}$ ), body mass index (BMI; $<25, \geq 25 \mathrm{~kg} / \mathrm{m}^{2}$ ), baseline HbAlc $(\leq 8.5 \%,>8.5 \%)$, concomitant SU therapy (yes [these patients may also have been receiving concomitant BG therapy], no), and concomitant BG therapy (yes [these patients may also have been receiving concomitant SU therapy], no).

Continuous variables (changes from baseline in HbA1c, body weight, and seated pulse rate) were analyzed with an analysis of covariance (ANCOVA) model with subgroup as a fixed effect and the baseline value as the covariate, with 2 exceptions: in the analysis of change from baseline in $\mathrm{HbAlc}$ by baseline $\mathrm{HbAlc}(\leq 8.5 \%,>8.5 \%)$, baseline $\mathrm{HbAlc}$ was not included as a covariate, and in the analysis of change from baseline in body weight by baseline body weight $(<70, \geq 70 \mathrm{~kg})$, baseline body weight was not included as a covariate. Least-square (LS) mean estimates, $95 \%$ confidence intervals (CIs), and descriptive statistics for the subgroup categories and differences between the subgroup categories were computed from the ANCOVA model, as well as $p$-values for the comparisons between the categories. For incidence variables (incidence of patients achieving target $\mathrm{HbA} 1 \mathrm{c}<7.0 \%$, hypoglycemia, and nausea), 2-sided $p$-values computed by Fisher's exact test were used to test the independence of the incidence and the subgroup categories. Statistical analyses were performed using SAS Version 9.2 (SAS Institute Inc, Cary, NC, USA).

\section{Results}

\section{Baseline demographic characteristics}

A total of 855 patients received at least 1 dose of dulaglutide $0.75 \mathrm{mg}$ in the 3 studies; Table 1 summarizes baseline characteristics for each of the 3 studies separately and overall. Approximately $75 \%$ of patients were male, and mean age \pm SD overall was approximately $57 \pm 10$ years. Mean duration of diabetes was $7.6 \pm 6.2$ years. Mean body weight was $71.3 \pm 13.1 \mathrm{~kg}$, and mean BMI was $25.9 \pm 3.6 \mathrm{~kg} / \mathrm{m}^{2}$. Mean $\mathrm{HbAlc}$ was $8.3 \pm 1.0 \%$; $65 \%$ of patients had $\mathrm{HbAlc}$ at baseline $\leq 8.5 \%$. Approximately $30 \%$ of patients were taking concomitant SU (with or without BG) and approximately $25 \%$ were taking concomitant BG (with or without SU). Table 2 and Table 3 summarize demographic and baseline characteristics by subgroups. Table 4 summarizes concomitant SU and BG doses.

\section{Subgroup analyses}

All analyses represent dulaglutide-treated patients pooled across the 3 studies after 26 weeks of treatment.

\section{Changes from baseline in HbA1c}

Fig. 1 presents a forest plot of analysis results for changes from baseline in HbA1c (\%) at week 26 by subgroup. The LS mean \pm SE change from baseline in $\mathrm{HbA} 1 \mathrm{c}$ at week 26 overall was $-1.60 \pm 0.03 \%$. There were statistically significant differences in changes from baseline in $\mathrm{HbA} 1 \mathrm{c}$ between the subgroup categories for age, BMI, body weight, and baseline $\mathrm{HbAlc}$. Reductions were significantly greater for older patients and those with lower BMI, lower body weight, and higher HbA1c: LS mean differences $(95 \% \mathrm{CIs})$ were $-0.12 \%(-0.24 \%,-0.01 \% ; p=0.034)$ for older younger patients, $-0.14 \%(-0.24 \%,-0.04 \% ; p=0.005)$ for patients with lower - higher BMI, $-0.21 \%(-0.30 \%$, $-0.11 \% ; p<0.001)$ for patients with lower - higher 
Table 1 Demographic and baseline characteristics of dulaglutide-treated patients overall and for each study

\begin{tabular}{|c|c|c|c|c|}
\hline & $\begin{array}{l}\text { Monotherapy study } \\
\qquad(\mathrm{n}=280)\end{array}$ & $\begin{array}{l}\text { BG/SU combination } \\
\text { study }(\mathrm{n}=181)\end{array}$ & $\begin{array}{l}\text { Long-term safety } \\
\text { study }(n=394)\end{array}$ & $\begin{array}{c}\text { Overall } \\
(\mathrm{N}=855)\end{array}$ \\
\hline Female, n (\%) & $52(19)$ & $56(31)$ & $98(25)$ & $206(24)$ \\
\hline Age, mean (SD), years & $57.2(9.6)$ & $57.5(10.5)$ & $57.4(11.0)$ & $57.3(10.4)$ \\
\hline Duration of T2D, mean (SD), years & $6.8(5.6)$ & $8.9(6.7)$ & $7.7(6.3)$ & $7.6(6.2)$ \\
\hline Weight, mean (SD), kg & $71.3(12.5)$ & $70.9(13.7)$ & $71.4(13.3)$ & $71.3(13.1)$ \\
\hline BMI, mean (SD), $\mathrm{kg} / \mathrm{m}^{2}$ & $25.6(3.6)$ & $26.1(3.6)$ & $25.9(3.7)$ & $25.9(3.6)$ \\
\hline HbA1c, mean (SD), \% & $8.2(0.8)$ & $8.1(0.8)$ & $8.5(1.1)$ & $8.3(1.0)$ \\
\hline Concomitant $\mathrm{SU}^{\mathrm{a}}, \mathrm{n}(\%)$ & $0(0)$ & $117(65)$ & $131(33)$ & $248(29)$ \\
\hline Concomitant $\mathrm{BG}^{\mathrm{b}}, \mathrm{n}(\%)$ & $0(0)$ & $147(81)$ & $61(16)$ & $208(24)$ \\
\hline \multicolumn{5}{|l|}{ Seated vital signs } \\
\hline SBP, mean (SD), mmHg & $128(13)$ & $129(14)$ & $131(14)$ & $130(14)$ \\
\hline DBP, mean $(\mathrm{SD}), \mathrm{mmHg}$ & $79(9)$ & $81(9)$ & $81(9)$ & $80(9)$ \\
\hline Pulse rate, mean (SD), bpm & $70(10)$ & $72(11)$ & $73(10)$ & $72(11)$ \\
\hline \multicolumn{5}{|l|}{ Hepatic function } \\
\hline ALT, mean (SD), U/L & $30(17)$ & $35(20)$ & $30(18)$ & $31(19)$ \\
\hline AST, mean (SD), U/L & $26(11)$ & $29(13)$ & $26(12)$ & $26(12)$ \\
\hline \multicolumn{5}{|l|}{ Renal function } \\
\hline UACR, mean (Q1, Q3), mg/g & $49(6,31)$ & $73(6,41)$ & $83(6,40)$ & $70(6,35)$ \\
\hline eGFR, mean (SD), $\mathrm{mL} / \mathrm{min} / 1.73 \mathrm{~m}^{2}$ & $75(16)$ & $76(17)$ & $73(16)$ & $74(16)$ \\
\hline Fasting insulin, mean (SD), mU/L & $9.1(6.5)$ & N/A & $9.9(7.3)$ & N/A \\
\hline Fasting c-peptide, mean (SD), ng/mL & $1.4(0.7)$ & N/A & $2.2(1.2)$ & N/A \\
\hline
\end{tabular}

ALT, alanine aminotransferase; AST, aspartate aminotransferase; BG, biguanides; BMI, body mass index; DBP, diastolic blood pressure; eGFR, estimated glomerular filtration rate; n/N, number of patients; N/A, not applicable; Q1, first quartile (25th percentile); Q3, third quartile (75th percentile); SBP, systolic blood pressure; SD, standard deviation; SU, sulfonylurea; T2D, type 2 diabetes; UACR, urine albumin/creatinine ratio. ${ }^{a}$ Includes patients taking SU with or without BG. ${ }^{\mathrm{b}}$ Includes patients taking BG with or without SU.

Table 2 Demographic and baseline characteristics in the subgroups (sex, age, duration of T2D, and body weight)

\begin{tabular}{|c|c|c|c|c|c|c|c|c|}
\hline & \multicolumn{2}{|c|}{ Sex } & \multicolumn{2}{|c|}{ Age } & \multicolumn{2}{|c|}{ Duration of T2D } & \multicolumn{2}{|c|}{ Body weight } \\
\hline & $\begin{array}{c}\text { Male } \\
(\mathrm{n}=649)\end{array}$ & $\begin{array}{l}\text { Female } \\
(\mathrm{n}=206)\end{array}$ & $\begin{array}{c}<65 \text { years } \\
(\mathrm{n}=641)\end{array}$ & $\begin{array}{c}\geq 65 \text { years } \\
(\mathrm{n}=214)\end{array}$ & $\begin{array}{l}<7 \text { years } \\
(\mathrm{n}=469)\end{array}$ & $\begin{array}{l}\geq 7 \text { years } \\
(\mathrm{n}=386)\end{array}$ & $\begin{array}{c}<70 \mathrm{~kg} \\
(\mathrm{n}=421)\end{array}$ & $\begin{array}{l}\geq 70 \mathrm{~kg} \\
(\mathrm{n}=434)\end{array}$ \\
\hline Female, n (\%) & $0(0)$ & $206(100)$ & $144(22)$ & $62(29)$ & $122(26)$ & $84(22)$ & $151(36)$ & $55(13)$ \\
\hline Age, mean (SD), years & $56.9(10.1)$ & $58.7(11.3)$ & $53.1(8.2)$ & $70.1(3.8)$ & $54.7(10.2)$ & $60.5(9.7)$ & $61.9(9.0)$ & $52.9(9.7)$ \\
\hline Duration of T2D, mean (SD), years & $7.7(6.2)$ & $7.6(6.3)$ & $6.7(5.6)$ & $10.5(7.1)$ & $3.5(1.9)$ & $12.7(5.9)$ & $9.0(6.9)$ & $6.3(5.1)$ \\
\hline Weight, mean (SD), kg & $73.9(12.4)$ & $62.8(11.7)$ & $73.9(12.9)$ & $63.4(10.2)$ & $73.0(13.2)$ & $69.1(12.7)$ & $60.7(6.4)$ & $81.5(9.2)$ \\
\hline BMI, mean (SD), $\mathrm{kg} / \mathrm{m}^{2}$ & $25.8(3.5)$ & $26.1(4.0)$ & $26.4(3.6)$ & $24.3(3.2)$ & $26.4(3.6)$ & $25.2(3.5)$ & $23.4(2.4)$ & $28.3(3.0)$ \\
\hline HbAlc, mean (SD), \% & $8.3(1.0)$ & $8.4(1.0)$ & $8.3(1.0)$ & $8.3(1.0)$ & $8.3(1.0)$ & $8.3(1.0)$ & $8.3(1.0)$ & $8.3(1.0)$ \\
\hline Concomitant $\mathrm{SU}^{\mathrm{a}}, \mathrm{n}(\%)$ & $177(27)$ & $71(34)$ & $171(27)$ & $77(36)$ & $100(21)$ & $148(38)$ & $133(32)$ & $115(26)$ \\
\hline Concomitant $\mathrm{BG}^{\mathrm{b}}, \mathrm{n}(\%)$ & $144(22)$ & $64(31)$ & $170(27)$ & $38(18)$ & $111(24)$ & $97(25)$ & $95(23)$ & $113(26)$ \\
\hline
\end{tabular}

BG, biguanides; BMI, body mass index; n, number of patients; SD, standard deviation; SU, sulfonylurea; T2D, type 2 diabetes. ${ }^{\text {a }}$ Includes patients taking SU with or without BG. ${ }^{\mathrm{b}}$ Includes patients taking BG with or without SU. 
Table 3 Demographic and baseline characteristics in the subgroups (BMI, HbA1c, concomitant SU, and concomitant BG)

\begin{tabular}{|c|c|c|c|c|c|c|c|c|}
\hline & \multicolumn{2}{|c|}{ BMI } & \multicolumn{2}{|c|}{$\mathrm{HbA1c}$} & \multicolumn{2}{|c|}{ Concomitant SU } & \multicolumn{2}{|c|}{ Concomitant BG } \\
\hline & $\begin{array}{c}<25 \mathrm{~kg} / \mathrm{m}^{2} \\
(\mathrm{n}=392)\end{array}$ & $\begin{array}{c}\geq 25 \mathrm{~kg} / \mathrm{m}^{2} \\
(\mathrm{n}=463)\end{array}$ & $\begin{array}{l}\leq 8.5 \% \\
(\mathrm{n}=559)\end{array}$ & $\begin{array}{c}>8.5 \% \\
(\mathrm{n}=296)\end{array}$ & $\begin{array}{c}\text { yes }^{\mathrm{a}} \\
(\mathrm{n}=248)\end{array}$ & $\begin{array}{c}\mathrm{no}^{\mathrm{b}} \\
(\mathrm{n}=607)\end{array}$ & $\begin{array}{c}\text { yes }^{\mathrm{c}} \\
(\mathrm{n}=208)\end{array}$ & $\begin{array}{c}\mathrm{no}^{\mathrm{d}} \\
(\mathrm{n}=647)\end{array}$ \\
\hline Female, n (\%) & $93(24)$ & $113(24)$ & $128(23)$ & $78(26)$ & $71(29)$ & $135(22)$ & $64(31)$ & $142(22)$ \\
\hline Age, mean (SD), years & $60.8(9.3)$ & $54.4(10.4)$ & $57.7(10.2)$ & $56.6(10.8)$ & $58.4(11.1)$ & $56.9(10.1)$ & $55.6(9.9)$ & $57.9(10.5)$ \\
\hline Duration of T2D, mean (SD), years & $9.1(7.0)$ & $6.4(5.2)$ & $7.5(6.1)$ & $8.0(6.4)$ & $9.7(7.0)$ & $6.8(5.7)$ & $8.1(6.4)$ & $7.5(6.2)$ \\
\hline Weight, mean (SD), kg & $61.8(7.9)$ & $79.3(11.2)$ & $70.8(12.8)$ & $72.1(13.6)$ & $70.2(13.0)$ & $71.7(13.1)$ & $72.8(13.1)$ & $70.8(13.1)$ \\
\hline BMI, mean (SD), $\mathrm{kg} / \mathrm{m}^{2}$ & $22.7(1.7)$ & $28.5(2.6)$ & $25.7(3.5)$ & $26.2(3.9)$ & $25.8(3.6)$ & $25.9(3.7)$ & $26.6(3.6)$ & $25.6(3.6)$ \\
\hline HbA1c, mean (SD), \% & $8.3(1.0)$ & $8.3(0.9)$ & $7.7(0.5)$ & $9.4(0.7)$ & $8.5(1.1)$ & $8.2(0.9)$ & $8.1(0.9)$ & $8.4(1.0)$ \\
\hline Concomitant SU, n (\%) & $121(31)$ & $127(27)$ & $137(25)$ & $111(38)$ & $248(100)$ & $0(0)$ & $83(40)$ & $165(26)$ \\
\hline Concomitant BG, $\mathrm{n}(\%)$ & $78(20)$ & $130(28)$ & $157(28)$ & $51(17)$ & $83(33)$ & $125(21)$ & $208(100)$ & $0(0)$ \\
\hline
\end{tabular}

BG, biguanides; BMI, body mass index; n, number of patients; SD, standard deviation; SU, sulfonylurea; T2D, type 2 diabetes.

${ }^{\mathrm{a}}$ Includes patients taking SU with or without BG. ${ }^{\mathrm{b}}$ Includes patients who may have been treated with diet and exercise, alpha-glucosidase inhibitors, thiazolidinediones, glinides, and/or BG. ${ }^{\mathrm{c}}$ Includes patients taking BG with or without SU. ${ }^{\mathrm{d}}$ Includes patients who may have been treated with diet and exercise, alpha-glucosidase inhibitors, thiazolidinediones, glinides, and/or SU.

Table 4 Daily dose of concomitant sulfonylurea and biguanide

\begin{tabular}{llrcc}
\hline \multirow{2}{*}{ Drug Class } & \multirow{2}{*}{ Drug name } & \multirow{2}{*}{$\mathrm{N}$} & \multicolumn{2}{c}{ Daily dose $(\mathrm{mg})$} \\
\cline { 4 - 5 } Sulfonylurea & Glibenclamide & 7 & $5.4 \pm 1.7$ & $4.3 \pm 2.4$ \\
& Gliclazide & 20 & $60 \pm 22$ & $58 \pm 25$ \\
& Glimepiride & 219 & $2.3 \pm 1.0$ & $2.1 \pm 1.0$ \\
\hline Biguanide & Buformin & 1 & 150 & 150 \\
& Metformin & 205 & $946 \pm 363$ & $917 \pm 398$ \\
\hline
\end{tabular}

Data are mean \pm SD.

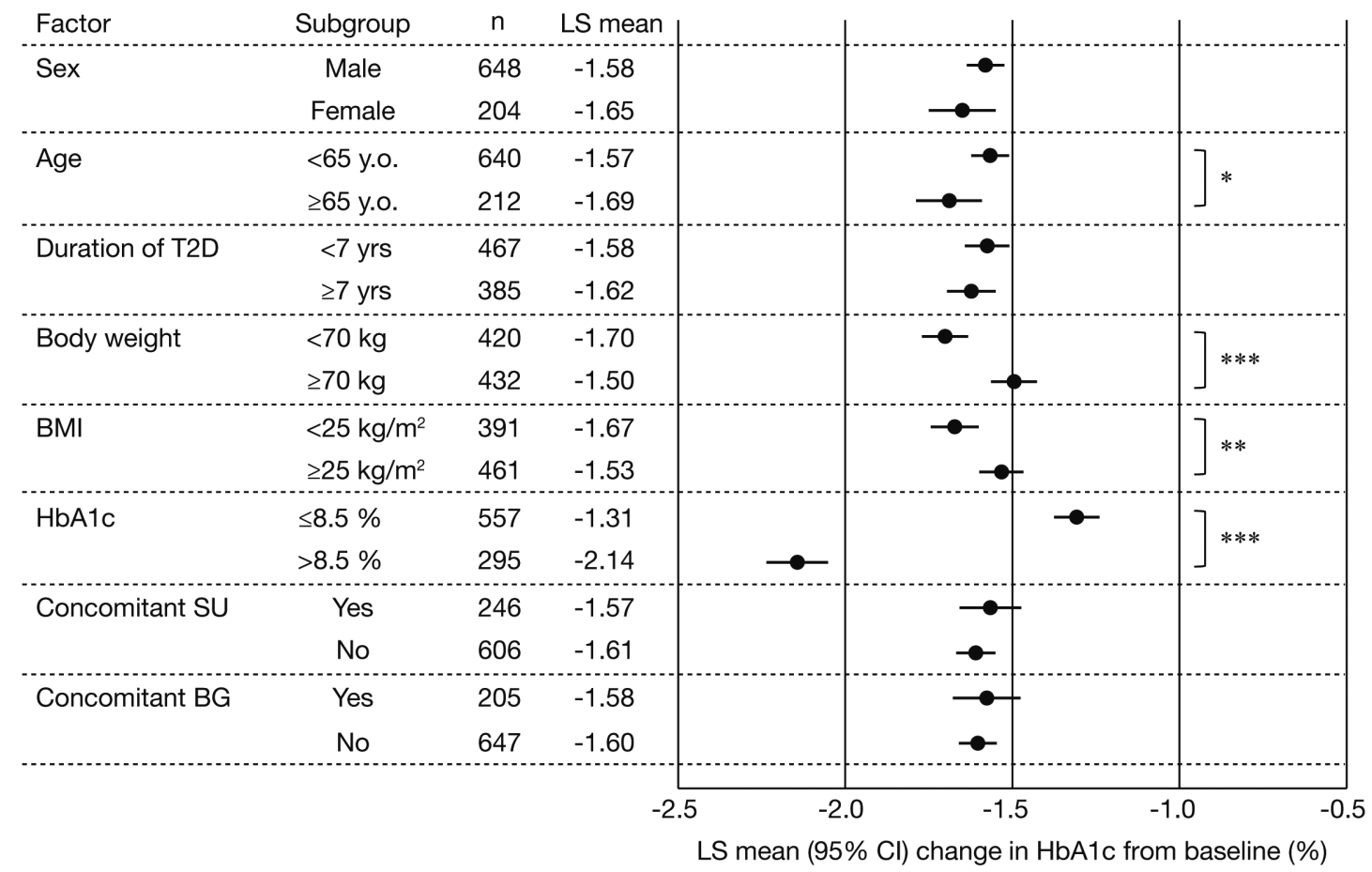

Fig. 1 LS mean $(95 \%$ CI) changes from baseline in HbA1c (\%) after 26 weeks for dulaglutide-treated patients by key subgroups. BG, biguanides; BMI, body mass index; CI, confidence interval; LS mean, least-square mean; n, number of patients with postbaseline data; SU, sulfonylurea; T2D, type 2 diabetes; yrs, years. * denotes $p<0.05, * *$ denotes $p<0.01$, *** denotes $p<0.001$ from $t$-tests. 
body weight, and $-0.84 \%(-0.95 \%,-0.72 \% ; p<0.001)$ for higher - lower HbAlc.

Percentages of patients achieving HbA1c $<7.0 \%$

Fig. 2 presents analysis results for percentages of patients achieving $\mathrm{HbA} 1 \mathrm{c}<7.0 \%$ at week 26 by subgroup. Overall, $71 \%$ of patients achieved $\mathrm{HbA} 1 \mathrm{c}$ $<7.0 \%$ by week 26 . There were statistically significant differences between the subgroup categories in patients achieving HbAlc $<7.0 \%$ for body weight $(76.4 \%$ [lower weight] vs. 65.3\% [higher weight], $p<0.001$ ), BMI (75.2\% [lower BMI] vs. 67.0\% [higher BMI], $p$ $=0.010)$, baseline HbAlc $(84.2 \%$ [lower HbAlc] $v s$. $45.4 \%$ [higher $\mathrm{HbA} 1 \mathrm{c}$ ], $p<0.001$ ), and concomitant SU use (73.6\% [no SU use] vs. 63.8\% [SU use], $p=0.006)$.

\section{Changes from baseline in body weight}

Fig. 3 presents a forest plot of analysis results for changes from baseline in body weight $(\mathrm{kg})$ at week 26 by subgroup. The LS mean change \pm SE from baseline in body weight at week 26 overall was $-0.18 \pm 0.08$ $\mathrm{kg}$. There were statistically significant differences in changes from baseline in body weight between the subgroup categories for sex, body weight, baseline $\mathrm{HbA1}$, and concomitant BG use: LS mean differences
(95\% CIs) were $-0.54 \mathrm{~kg}(-0.95,-0.13 ; p=0.011)$ for females - males, $-0.50 \mathrm{~kg}(-0.83,-0.17 ; p=0.003)$ for patients with lower - higher weight, $0.96 \mathrm{~kg}(0.62$, $1.30 ; p<0.001)$ for higher - lower HbAlc, and -0.70 $\mathrm{kg}(-1.09,-0.32 ; p<0.001)$ for patients with BG use no BG use.

\section{Percentages of patients experiencing hypoglycemia}

Fig. 4 presents analysis results for percentages of patients experiencing hypoglycemia through week 26 by subgroup. Overall, $12 \%$ of patients experienced hypoglycemia. There were statistically significant differences in incidence of hypoglycemia between the subgroup categories for age (19.6\% [older patients] $v s$. $9.2 \%$ [younger patients], $p<0.001$ ), duration of diabetes $(16.1 \%$ [longer duration] vs. $8.3 \%$ [shorter duration], $p<0.001)$, baseline body weight $(14.7 \%$ [lower weight] $v s .9 .0 \%$ [higher weight], $p=0.011$ ), concomitant SU use (30.6\% [SU use] vs. 4.1\% [no SU use], $p$ $<0.001)$, and concomitant BG use (17.3\% [BG use] vs. $10.0 \%$ [no BG use], $p=0.006$ ).

\section{Percentages of patients experiencing nausea}

Fig. 5 presents analysis results for percentages of patients experiencing nausea through week 26 by sub-

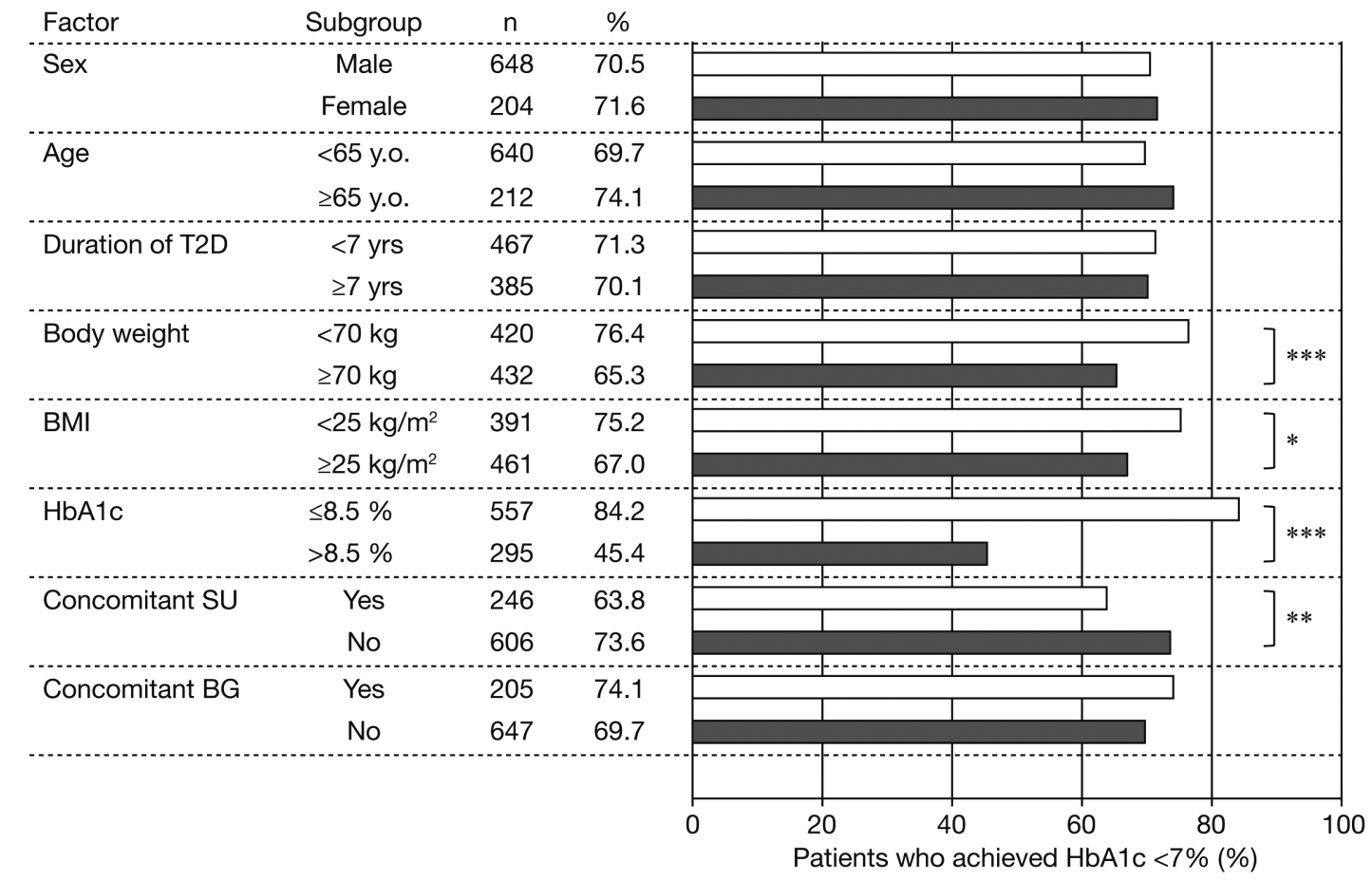

Fig. 2 Percentages of dulaglutide-treated patients achieving HbAlc $<7.0 \%$ (\%) after 26 weeks by key subgroups. BG, biguanides; BMI, body mass index; $n$, number of patients with postbaseline data; SU, sulfonylurea; T2D, type 2 diabetes; yrs, years.

$*$ denotes $p<0.05$, ** denotes $p<0.01$, *** denotes $p<0.001$ from Fisher's exact tests. 


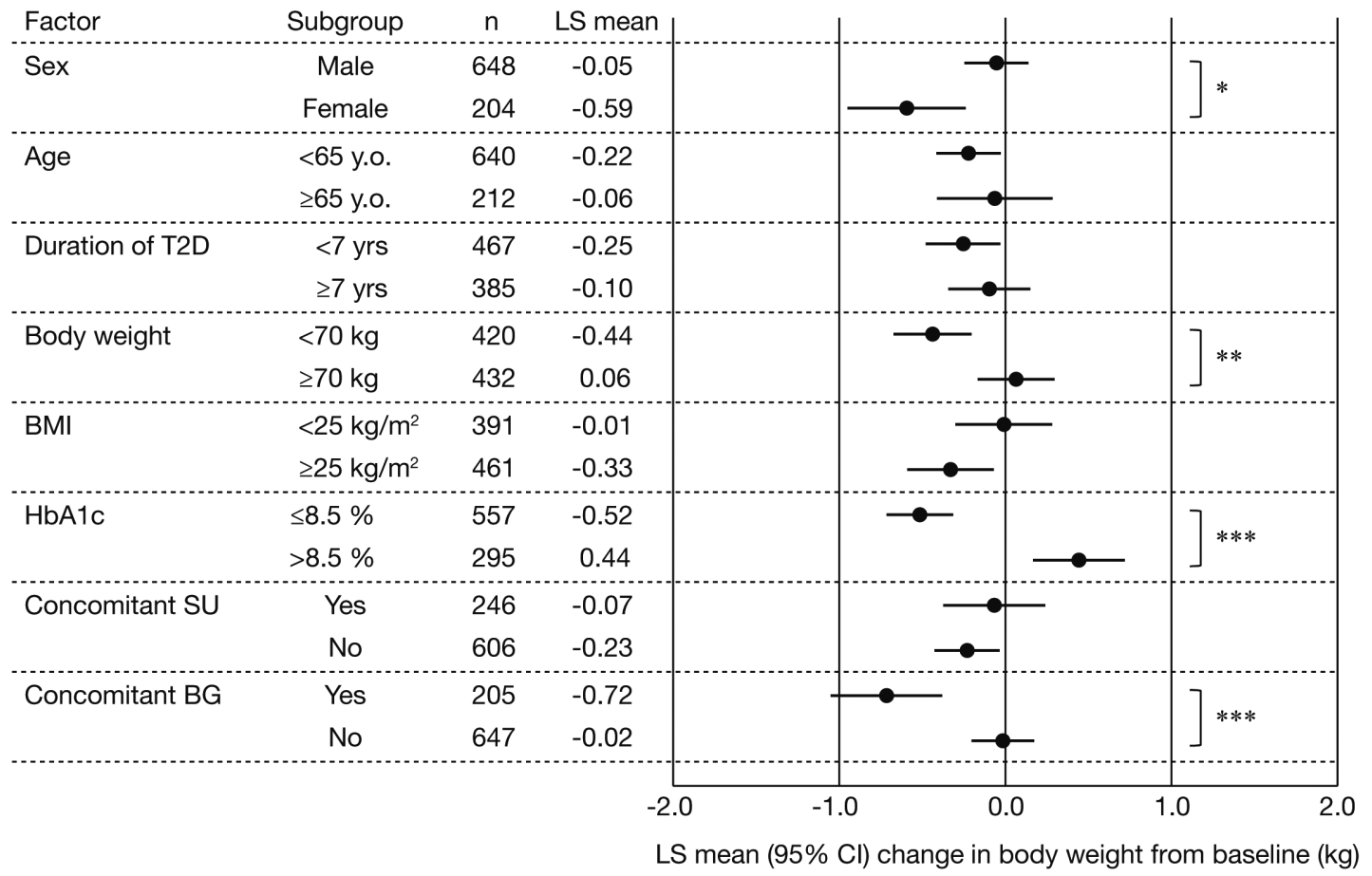

Fig. 3 LS mean $(95 \% \mathrm{CI})$ changes from baseline in body weight $(\mathrm{kg})$ after 26 weeks for dulaglutide-treated patients by key subgroups. BG, biguanides; BMI, body mass index; CI, confidence interval; LS mean, least-square mean; n, number of patients with postbaseline data; SU, sulfonylurea; T2D, type 2 diabetes; yrs, years. * denotes $p<0.05, * *$ denotes $p<0.01, * * *$ denotes $p<0.001$ from $t$-tests.

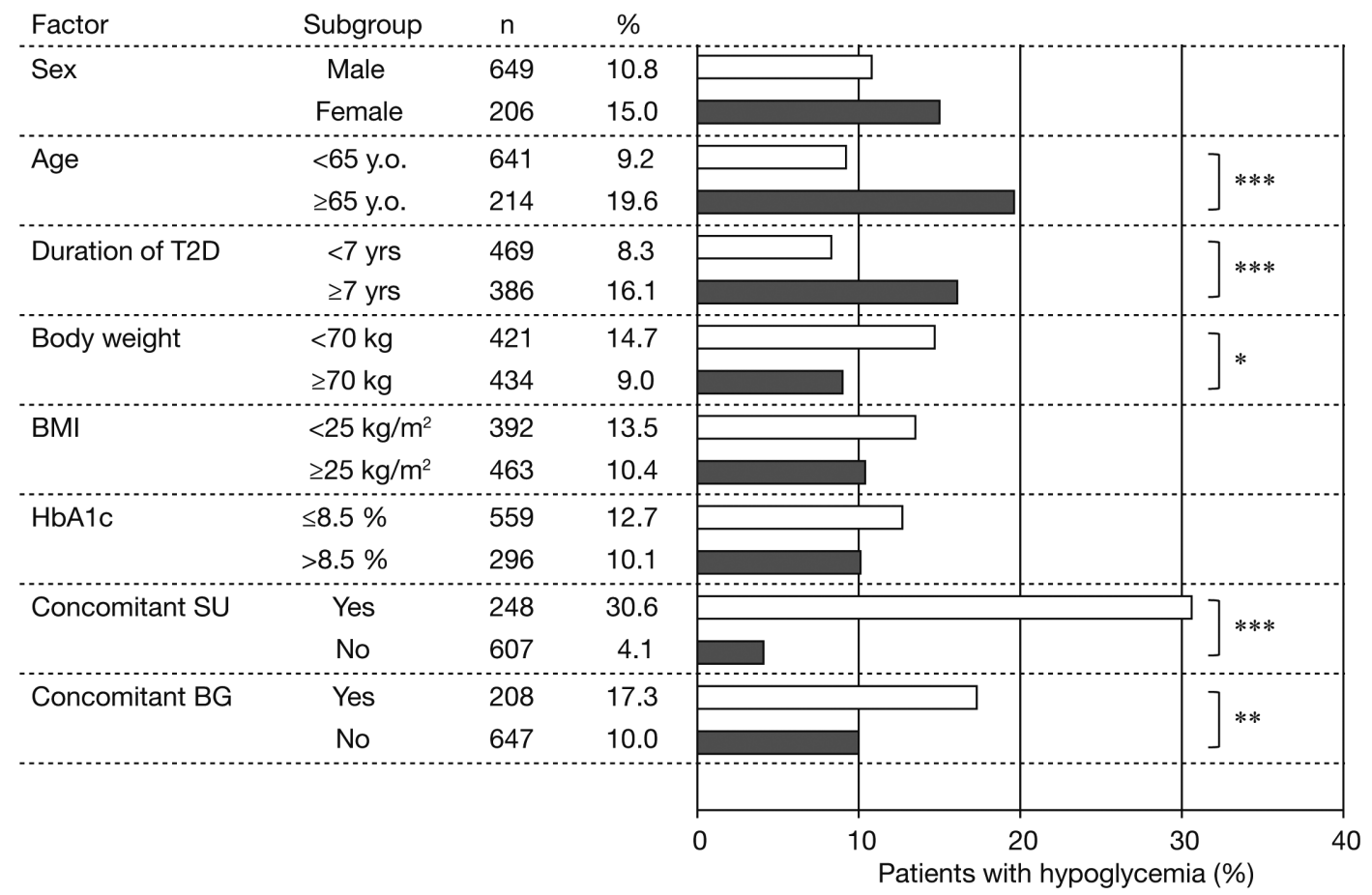

Fig. 4 Percentages of dulaglutide-treated patients experiencing hypoglycemia (\%) through 26 weeks by key subgroups. BG, biguanides; BMI, body mass index; n, number of patients with postbaseline data; SU, sulfonylurea; T2D, type 2 diabetes; yrs, years. * denotes $p<0.05$, ** denotes $p<0.01, * * *$ denotes $p<0.001$ from Fisher's exact tests. 


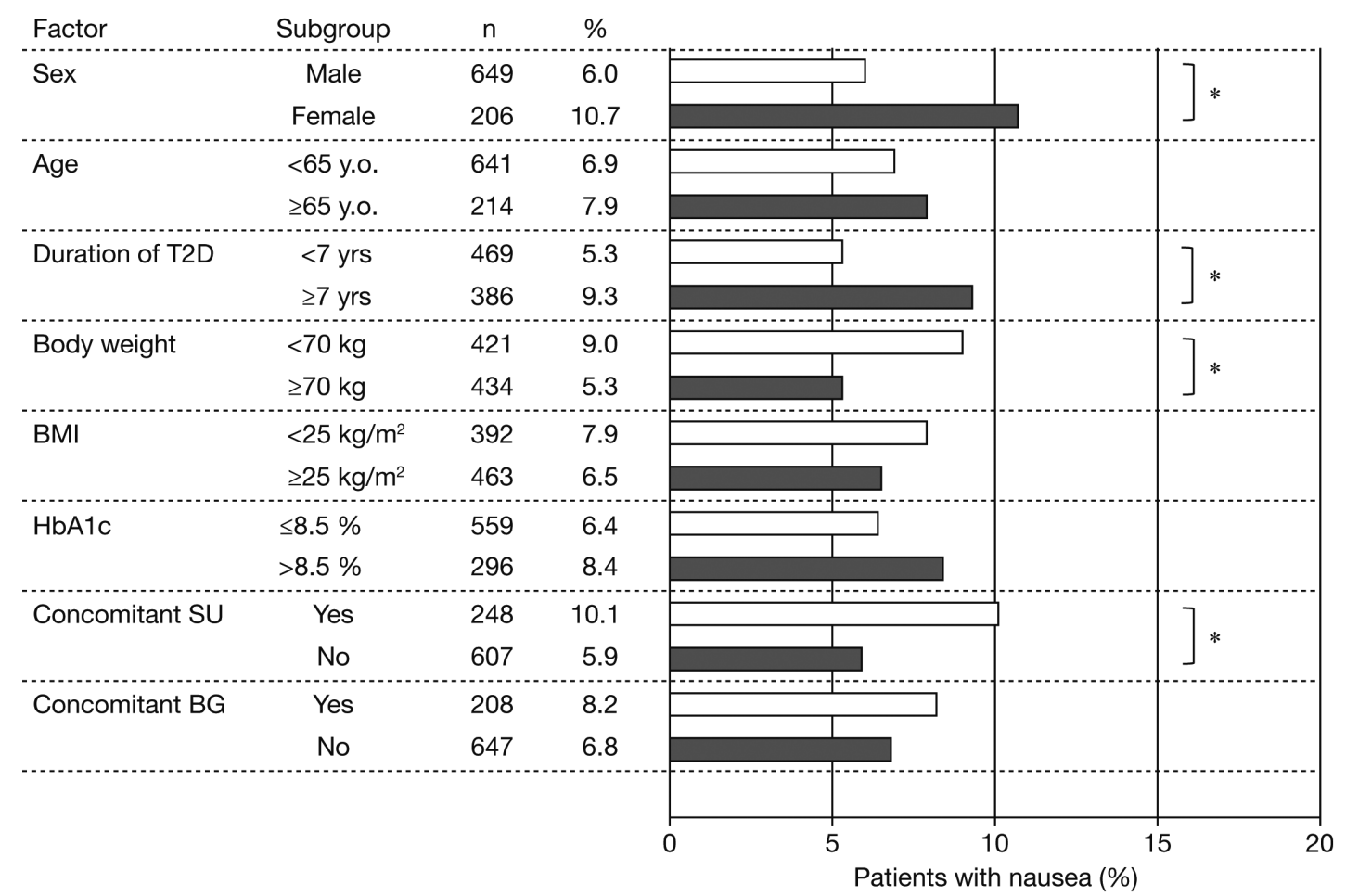

Fig. 5 Percentages of dulaglutide-treated patients experiencing nausea (\%) through 26 weeks by key subgroups. BG, biguanides; BMI, body mass index; n, number of patients with postbaseline data; SU, sulfonylurea; T2D, type 2 diabetes; yrs, years.

* denotes $p<0.05$ from Fisher's exact tests.

group. Overall, $7.1 \%$ of patients experienced nausea. There were statistically significant differences in incidence of nausea between the subgroup categories for $\operatorname{sex}(10.7 \%$ [females] vs. $6.0 \%$ [males]; $p=0.029)$, body weight $(9.0 \%$ [lower weight] vs. $5.3 \%$ [higher weight]; $p=0.045)$, duration of diabetes $(9.3 \%$ [longer duration] vs. 5.3\% [shorter duration]; $p=0.032$ ), and concomitant SU use (10.1\% [SU use] vs. 5.9\% [no SU use]; $p=0.040$ ).

\section{Changes from baseline in seated pulse rate}

Fig. 6 presents a forest plot of analysis results for changes from baseline in seated pulse rate (bpm) at week 26 by subgroup. The LS mean change \pm SE from baseline in seated pulse rate at week 26 overall was $2.9 \pm 0.3 \mathrm{bpm}$. There were statistically significant differences in changes from baseline in pulse rate between the subgroup categories for age, body weight, and baseline HbAlc: LS mean $(95 \% \mathrm{CI})$ differences were $-1.27 \mathrm{bpm}(-2.34,-0.20 ; p=0.020)$ for older younger patients, $-0.92 \mathrm{bpm}(-1.84,-0.00 ; p=0.050)$ for patients with lower - higher weight, and $1.11 \mathrm{bpm}$ $(0.15,2.08 ; p=0.024)$ for patients with higher - lower HbA1c, respectively.

\section{Discussion}

This post hoc analysis of three Japanese phase 3 studies of once weekly dulaglutide $0.75 \mathrm{mg}$ evaluated efficacy and safety data after 26 weeks of treatment stratified by sex, age, body weight, BMI, duration of diabetes, baseline $\mathrm{HbA1c}$, and use of concomitant SU or BG. This is the first analysis of dulaglutide across subgroups; these stratification factors have also been used in previous pooled subgroup analyses for other GLP-1 receptor agonists, such as liraglutide [11, 12], exenatide twice daily [13], exenatide once weekly [14], and lixisenatide [15].

Treatment with once weekly dulaglutide $0.75 \mathrm{mg}$ resulted in significant reductions from baseline in $\mathrm{HbA} 1 \mathrm{c}$ in all of the subgroups analyzed. In the present analysis the most influential factor for reduction in $\mathrm{HbA} 1 \mathrm{c}$ and achievement of $\mathrm{HbA} 1 \mathrm{c}<7.0 \%$ was $\mathrm{HbA} 1 \mathrm{c}$ value at baseline: patients with higher baseline $\mathrm{HbAlc}$ had significantly greater $\mathrm{HbA} 1 \mathrm{c}$ reductions from baseline, but a significantly smaller percentage achieved HbAlc $<7.0 \%$ compared to patients with lower baseline $\mathrm{HbA} 1 \mathrm{c}$. Similar results were reported in a pooled 


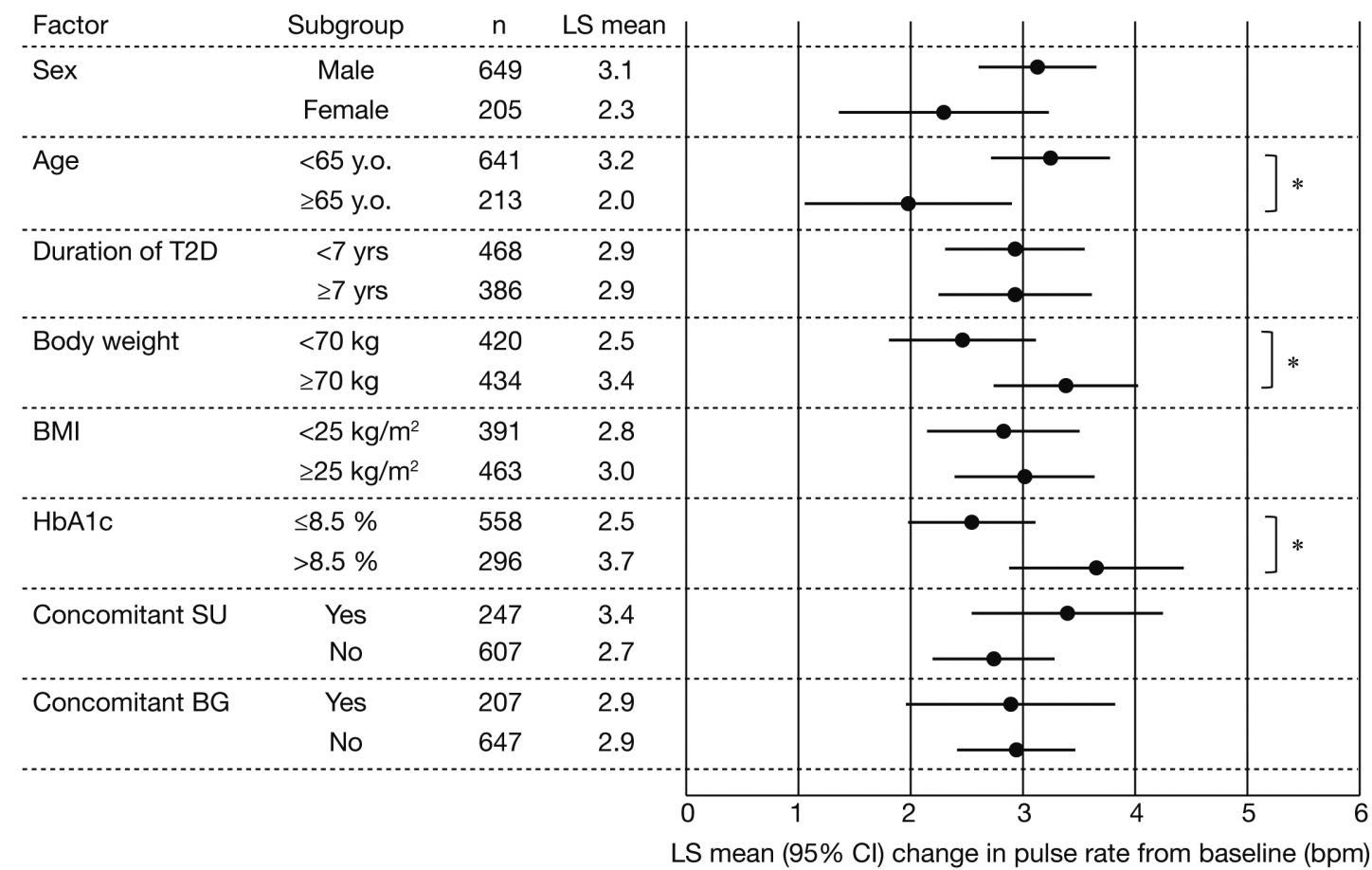

Fig. 6 LS mean $(95 \% \mathrm{CI})$ changes from baseline in seated pulse rate (bpm) after 26 weeks for dulaglutide-treated patients by key subgroups. BG, biguanides; BMI, body mass index; bpm, beats per minute; CI, confidence interval; LS mean, least-square mean; $\mathrm{n}$, number of patients with postbaseline data; SU, sulfonylurea; T2D, type 2 diabetes; yrs, years. * denotes $p<0.05$ from $t$-tests.

analysis of liraglutide studies [12]. In that analysis, greater $\mathrm{HbAlc}$ reductions were observed in patients with higher baseline $\mathrm{HbAlc}$ after 26 weeks of treatment compared to patients with lower HbAlc at baseline whether they were treated with liraglutide or comparators such as sitagliptin, glimepride, rosiglitazone, exenatide, or insulin glargine. Similarly, patients with lower baseline $\mathrm{HbAlc}$ were more likely to achieve HbAlc $<7.0 \%$ after 26 weeks of treatment compared to patients with higher baseline $\mathrm{HbAlc}$ regardless of treatment. Differences in changes in HbAlc among the other subgroups analyzed were generally small and were of limited clinical significance.

In our analysis of once weekly dulaglutide, statistically significantly greater reductions from baseline in body weight were observed in female patients and in patients who had lower body weight or lower $\mathrm{HbAlc}$ at baseline or were using concomitant BG compared to other patients. The effects of sex and baseline body weight might be confounded because females had lower mean body weight compared to males (62.8 vs. $73.9 \mathrm{~kg}$ ). Higher serum concentrations of dulaglutide in females might result in a more potent weight-loss effect. The detailed mechanism resulting in increased weight loss when GLP-1 receptor agonist therapy is combined with $\mathrm{BG}$ is unknown. However, it has been reported that BG enhances intrinsic GLP-1 secretion, and this might explain the additive effect on weight loss $[16,17]$. Patients using concomitant BG in a previous phase 3 study of liraglutide in Japan had weight loss similar to that reported here [18]. The observation in this analysis of greater weight loss in patients with lower baseline $\mathrm{HbAlc}$ compared to those with higher $\mathrm{HbA} 1 \mathrm{c}$ was unexpected. There is no obvious interpretation for this phenomenon, but one possible interpretation is that higher $\mathrm{HbAlc}$ levels reflected the difficulty of treatment of diabetes, including control of body weight, in this population. Differences in usage of concomitant medications might also have affected these results: patients with higher baseline $\mathrm{HbA1c}$ used SU more frequently (38\%) and BG less frequently (17\%) compared to patients with lower baseline HbA1c (25\% used SU, 28\% used BG).

Overall, the incidence of hypoglycemia observed in the studies was low, with the exception of patients with concomitant SU use. Concomitant use of SU with GLP-1 receptor agonists is a known risk for hypoglycemia, and the Japan Diabetes Society Committee 
for proper use of incretin drugs (GLP-1 receptor agonists and DPP-4 inhibitors) recommends reducing concomitant SU doses when treatment with incretin drugs such as DPP-4 inhibitors or GLP-1 receptor agonists is begun [19]. Concomitant use of BG also increased the incidence of hypoglycemia in this analysis, but $40 \%$ of patients taking concomitant BG were also taking concomitant SU. Incidence of hypoglycemia in patients taking concomitant BG only (without $\mathrm{SU}$ ) was $7.2 \%$, while incidence in patients taking $\mathrm{BG}$ and $\mathrm{SU}$ was $32.5 \%$. Higher incidence of hypoglycemia was also observed in older patients ( $\geq 65$ years [mean age 70.1 years]). Compared to younger patients ( $<65$ years [mean age 53.1 years]), the older patients had longer mean duration of diabetes (10.5 vs. 6.7 years), lower mean body weight (63.4 vs. $73.9 \mathrm{~kg}$ ), and were more likely to be receiving concomitant SU (36\%vs. 27\%). Hypoglycemia is a frequently observed adverse event in older patients; in these patients, autonomic symptoms are diminished and symptom intensity is low overall [20].

Incidence of nausea was relatively low in all subgroups. In this study, higher incidences of nausea were observed in females and in patients with longer duration of diabetes, lower baseline body weight, and concomitant use of SU compared to other patients. There were statistically significant effects but no clinically significant effects of subgroups on nausea. As mentioned previously, the effects of sex and baseline body weight might be confounded, and higher serum concentrations of dulaglutide might have increased the incidence of nausea. In addition, the effects of duration of diabetes and concomitant SU use were confounded because mean duration of T2D in patients using concomitant SU was longer than that in patients not using concomitant SU (9.7 vs. 6.8 years). One of the causes of nausea is delayed gastric emptying, and the main cause of delayed gastric emptying in patients with T2D is autonomic neuropathy, which worsens in patients with longer duration of diabetes [21].

In the analyses of pulse rates, there were statistically significant differences between the subgroup categories for age, body weight, and baseline $\mathrm{HbAlc}$; however, the differences were not clinically significant.

Subgroup analyses by age groups are the most commonly reported: analyses for liraglutide, exenatide twice daily, exenatide once weekly, and lixisenatide have been published [11, 13-15]. In this analysis of dulaglutide studies, elderly patients ( $\geq 65$ years) had significantly greater reductions in $\mathrm{HbAlc}$, significantly higher incidence of hypoglycemia, and significantly smaller increases in pulse rate compared to younger patients. In a pooled analysis of the six Liraglutide Effect and Action in Diabetes (LEAD) studies [11], there were no statistically significant differences in changes from baseline in HbAlc or body weight between age groups ( $<65$ or $\geq 65$ years). The proportions of patients reporting minor hypoglycemia were low and appeared comparable between the age groups. In a posthoc analysis of 16 randomized studies of exenatide twice daily [13], the changes from baseline in $\mathrm{HbA} 1 \mathrm{c}$ and fasting plasma glucose were similar between the age groups, but greater weight loss was observed for elderly patients ( $\geq 65$ years) compared to younger patients. In a posthoc analysis of 7 randomized studies of exenatide once weekly [14], changes from baseline in $\mathrm{HbAlc}$, fasting plasma glucose, and body weight were similar for both age groups $(<65$, $\geq 65$ years). In a pooled analysis of 6 randomized studies of lixisenatide [15], the incidences of treatmentemergent adverse events and symptomatic hypoglycemia were generally numerically higher in the elderly group ( $\geq 65$ years) who received lixisenatide but were generally comparable between the age groups.

The subgroup analyses of the studies reported here had some potential limitations. First, these were posthoc, exploratory analyses using data integrated from studies with different designs (i.e., randomized and non-randomized, double-blind and open-label). Second, the types of patients included were limited to some extent, as exemplified by the low proportions of females and of patients over 75 years of age and by the exclusion of patients with clinically significant medical conditions such as renal and hepatic disorders. Third, the current subgroup analyses adjusted only for baseline values for continuous variables ( $\mathrm{HbA} 1 \mathrm{c}$, body weight, and pulse rate) but not for other potential confounding factors that may have affected the results.

In conclusion, once weekly dulaglutide $0.75 \mathrm{mg}$ improved blood glucose control as measured by HbA1c regardless of patient characteristics other than baseline $\mathrm{HbA} 1 \mathrm{c}$ value. Weight loss was greatest in patients with lower baseline $\mathrm{HbA} 1 \mathrm{c}$ and in patients taking concomitant BG. Concomitant use of SU had the greatest effect on incidence of hypoglycemia. While statistically significant differences were observed between some patient characteristic subgroups (for example, younger $v s$. older patients) for other clinical outcomes, 
in general these differences were not considered clinically relevant.

\section{Acknowledgement}

The authors thank Mary Re of inVentiv Health Clinical, and Akiko Matsui, PhD, of Eli Lilly Japan K.K. for assistance with writing.

\section{Declaration of Interest}

Y.O. has received honoraria for lectures from Novo Nordisk Pharma Ltd., MSD K.K., Eli Lilly Japan K.K., Sumitomo Dainippon Pharma Co., Ltd., and Nippon Boehringer Ingelheim Co., Ltd. T.O., H.N., S.O., M.T., and N.I. are employees of Eli Lilly Japan K.K., and
M.T. has the company stock option.

\section{Funding Source}

This study was sponsored by Eli Lilly and Company.

\section{Author Contributions}

Y.O. was a trial investigator and participated in data collection. T.O., H.N., S.O., M.T., and N.I. prepared the first draft of the manuscript. T.O. and H.N. were responsible for the statistical considerations. All authors participated in reviewing and interpreting the data and providing comments and revisions to the manuscript. All authors approved the final version of the manuscript and take full responsibility for the content.

\section{References}

1. American Diabetes Association (2015) Approaches to glycemic treatment. Diabetes Care 38 (Suppl 1): S41-48.

2. Japan Diabetes Society (2013) Treatment guide for diabetes. Available at http://www.jds.or.jp/common/ fckeditor/editor/filemanager/connectors/php/transfer. php?file=/uid000025 54726561746D656E745F47756 964655F666F725F44696162657465735F323031322D 323031332E706466. Accessed 18 June 2015.

3. Glaesner W, Vick AM, Millican R, Ellis B, Tschang $\mathrm{SH}$, et al. (2010) Engineering and characterization of the long-acting glucagon-like peptide-1 analogue LY2189265, an Fc fusion protein. Diabetes Metab Res Rev 26: 287-296.

4. Trulicity [Prescribing Information]. Indianapolis, IN: Eli Lilly and Company 2015. Available at http://pi.lilly. com/us/trulicity-uspi.pdf. Accessed 18 June 2015.

5. Trulicity [Summary of Product Characteristics]. Houten, The Netherlands: Eli Lilly and Company 2015. Available at http://www.ema.europa.eu/docs/en_GB/document library/EPAR__Product_Information/human/002825/ WC500179470.pdf. Accessed 10 July 2015.

6. Trulicity Ateos [Japan package insert]. Hyogo Japan: Eli Lilly Japan K.K. 2016. Available at http://www.info.pmda.go.jp/downfiles/ph/PDF/ 530471_2499416G1029_1_04.pdf (In Japanese). Accessed 2 March 2016.

7. Miyagawa J, Odawara M, Takamura $T$, Iwamoto $\mathrm{N}$, Takita Y, et al. (2015) Once-weekly glucagon-like peptide-1 receptor agonist dulaglutide is non-inferior to once-daily liraglutide and superior to placebo in Japanese patients with type 2 diabetes: a 26-week randomized phase III study. Diabetes Obes Metab 17: 974-983.

8. Odawara M, Miyagawa J, Iwamoto N, Takita Y, Imaoka
T, et al. (2016) Once weekly glucagon-like peptide-1 receptor agonist dulaglutide significantly decreases HbA1c compared with once daily liraglutide in Japanese patients with type 2 diabetes: 52 weeks of treatment in a randomized phase III study. Diabetes Obes Metab 18: 249-257.

9. Araki E, Inagaki N, Tanizawa Y, Oura T, Takeuchi M, et al. (2015) Efficacy and safety of once-weekly dulaglutide in combination with sulphonylurea and/or biguanide compared with once-daily insulin glargine in Japanese patients with type 2 diabetes: a randomized, open-label, phase III, non-inferiority study. Diabetes Obes Metab 17: 994-1002.

10. Emoto M, Terauchi Y, Ozeki A, Oura T, Takeuchi M, et al. (2015) A 1-year safety study of dulaglutide in Japanese patients with type 2 diabetes on a single oral hypoglycemic agent: an open-label, nonrandomized, phase 3 trial. Endocr J 62: 1101-1114.

11. Bode BW, Brett J, Falahati A, Pratley RE (2011) Comparison of the efficacy and tolerability profile of liraglutide, a once-daily human GLP-1 analog, in patients with type 2 diabetes $\geq 65$ and $<65$ years of age: a pooled analysis from phase III studies. Am J Geriatr Pharmacother 9: 423-433.

12. Henry RR, Buse JB, Sesti G, Davies MJ, Jensen KH, et al. (2011) Efficacy of antihyperglycemic therapies and the influence of baseline hemoglobin $\mathrm{A}(1 \mathrm{C})$ : a meta-analysis of the liraglutide development program. Endocr Pract 17: 906-913.

13. Pencek R, Blickensderfer A, Li Y, Brunell SC, Anderson PW (2012) Exenatide twice daily: analysis of effectiveness and safety data stratified by age, sex, race, duration of diabetes, and body mass index. Postgrad Med 124: 
21-32.

14. Pencek R, Brunell SC, Li Y, Hoogwerf BJ, Malone J (2012) Exenatide once weekly for the treatment of type 2 diabetes mellitus: clinical results in subgroups of patients using different concomitant medications. Postgrad Med 124: 33-40.

15. Raccah D, Miossec P, Esposito V, Niemoeller E, Cho $M$, et al. (2015) Efficacy and safety of lixisenatide in elderly ( $\geq 65$ years old) and very elderly ( $\geq 75$ years old) patients with type 2 diabetes: an analysis from the GetGoal phase III programme. Diabetes Metab Res Rev 31: 204-211.

16. Mulherin AJ, Oh AH, Kim H, Grieco A, Lauffer LM, et al. (2011) Mechanisms underlying metformin-induced secretion of glucagon-like peptide-1 from the intestinal L cell. Endocrinology 152: 4610-4619.

17. Kim MH, Jee JH, Park S, Lee MS, Kim KW, et al. (2014) Metformin enhances glucagon-like peptide 1 via cooperation between insulin and Wnt signaling. $J$
Endocrinol 220: 117-128.

18. Pharmaceuticals and Medical Devices Agency (2014) Review report for new indication of liraglutide (Victoza). Available at http://www.pmda.go.jp/drugs/2014/P2014 00122/620023000_22200AMX00236_A100_1.pdf (In Japanese). Accessed 10 August 2015.

19. Japan Diabetes Society (2011) Committee on the proper use of incretin drugs (GLP-1 receptor agonists and DPP-4 inhibitors). Available at http://www.fa.kyorin.co.jp/ jds/uploads/photos/797.pdf (In Japanese). Accessed 18 June 2015.

20. Sinclair A, Dunning T, Rodriguez-Mañas L (2015) Diabetes in older people: new insights and remaining challenges. Lancet Diabetes Endocrinol 3: 275-285.

21. Lehmann R, Borovicka J, Kunz P, Crelier G, Boesiger $P$, et al. (1996) Evaluation of delayed gastric emptying in diabetic patients with autonomic neuropathy by a new magnetic resonance imaging technique and radioopaque markers. Diabetes Care 19: 1075-1082. 